\title{
NONCONVEX FUNCTIONS AND SEPARATION BY POWER MEANS
}

\author{
ZSOLT PÁLES
}

Abstract. In this note we show that, for a nonconvex function defined on a real interval, there exists a point where this function behaves like a strictly concave function. Due to this result, global convexity can be characterized as pointwise convexity everywhere. As an application, a necessary and sufficient condition for the separability of quasiarithmetic means with power means is obtained.

Mathematics subject classification (1991): Primary 26A51, 26 B25.

Key words and phrases: Convexity, quasiarithmetic means, power means, separation.

\section{REFERENCES}

[1] G. H. Hardy, J. E. Littlewood, And G. Pólya, Inequalities, Cambridge Univ. Press, Cambridge New York - London, 1934 (first edition), 1952 (second edition).

[2] M. Kuczma, An Introduction to the Theory of Functional Equations and Inequalities, Państwowe Wydawnictwo Naukowe, Warszawa - Kraków - Katowice, 1985.

[3] Zs. PÁLES, Hölder-type inequalities for quasiarithmetic means, Acta Math. Hung., 47 (1986), 395-399.

[4] A. W. Roberts And D. E. VArberG, Convex Functions, Academic Press, New York - London, 1973. 